\title{
The Western Balkan Countries in the Face of the Covid-19 Pandemic: Policy Recommendations
}

\section{Study Group Regional Stability in South East Europe}

Partnership for Peace Consortium of Defense Academies and Securit Studies Institutes, https://pfp-consortium.org/

\begin{abstract}
These policy recommendations reflect the findings of the First Virtual Meeting on "The Western Balkan Countries in the Face of the COVID-19 Pandemic," convened by the PfP Consortium Study Group "Regional Stability in Southeast Europe," 28 May 2020. The article includes a number of tangible suggestions for Western Balkan governments, as well as for the EU, EU member states and NATO deciion-makers on how to confront the coronavirus and security-related challenges in Southeast Europe.
\end{abstract}

Keywords: COVID-19, situation analysis, policy recommendations, Albania, Bosnia and Herzegovina, Kosovo, Montenegro, North Macednia, Serbia

\section{Executive Summary of Recommendations ${ }^{1}$ :}

- Western Balkan (WB) governments and EU: Health systems should be supported with funds from the EU's announced $€ 3.3$ billion support package and other Western sources.

1 These policy recommendations were prepared by Predrag Jureković (Austrian National Defence Academy, Vienna) on the basis of proposals submitted by the webinar participants. Valuable support in proofreading and layouting came from Benedikt Hensellek and Lisa Tagwercher (Austrian National Defence Academy, Vienna). The participants of this webinar were (in alphabetical order): Milena Bešić (Center for Democracy and Human Rights, Podgorica), Alba Cela (Albanian Institute for International Studies, Tirana), Filip Ejdus (University of Belgrade), Benedikt Hensellek, Predrag Jureković, Sandro Knezović (Institute for Development and International Relations, Zagreb), Magdalena Lembovska (Eurothink, Skopje), Lulzim Peci (The Kosovar Institute for Policy Research and Development, Prishtina/Priština), Djordje Popović (Belgrade 
- $\quad W B$ gov.: Public funds dedicated to the crisis to be used transparently and any opportunities for corruption to be curtailed.

- WB gov., EU and Regional Cooperation Council (RCC): The less nationalistic regional climate should be used as a starting point for structured regional cooperation in the fight against the pandemic, which should also be promoted by the EU Commission and the RCC in Sarajevo.

- WB gov.: The clear separation of executive and legislative powers should be restored. Decisions by the constitutional courts relating to COVID-19 measures should be implemented and the monitoring role of ombudspersons and NGOs respected.

- EU and other international stakeholders: The independence of the judiciary should be further strengthened, with special attention given to the use of public funds during the crisis. Any misuse of public funds by politicians during the crisis should be publicly condemned, as should any other individuals involved.

- EU and OSCE: Election monitoring should be intensified as well as the commitment to free media coverage in light of upcoming parliamentary or local elections.

- EU Special Representative (EUSR) for the WB: The EUSR should engage proactively in order to demonstrate a serious interest in the region's democratic development and to contribute to constructive conflict resolution within and between the individual WB countries.

- EU: A more accountable and dynamic integration policy vis-à-vis the entire WB should be started. A visa-free regime should be granted to Kosovo without further delay.

- EU: Contradictory signals within the EU on important issues of peace consolidation should be avoided (e.g., Josep Borrell and Miroslav Lajčák on Kosovo).

- EU and US: A clear common EU-US line on the Belgrade-Prishtina/Priština dialogue and other core topics of regional consolidation should be restated.

\section{Situation Analysis}

Despite a moderate course of COVID-19 in the WB to date, the epidemic has revealed blatant weaknesses in the resilience of regional health systems. The crisis showed that there is a severe shortage of medical protective equipment and equipment for intensive care in the region. In both areas, there is a high degree of dependence on foreign actors. There was a lack of preventive plans and measures concerning a pandemic. In view of the low resilience of the healthcare systems, a moderate course of COVID-19 in the WB could only be achieved

Fund for Political Excellence), Denisa Sarajlić (Independent Consultant, Sarajevo) and Marcel Szalai (PfP Consortium Operations Staff, Garmisch-Partenkirchen). 
through rigorous curfews. They were based on partly authoritarian and nontransparent decisions of politicians, bypassing parliaments and their constitutional rights.

For example, a state of emergency in Serbia was proclaimed in an unconstitutional way with the false claim that parliament was not able to meet. The rule of law and separation of powers were almost completely abolished in most of the WB countries during the peak of the crisis. According to regional Think Tanks and human rights organizations, this was followed by many examples of human rights violations - such as a disproportional limitation of the freedom of movement, violation of media freedoms, and of the right to a fair trial. Even though the rigorous measures were eased again from May onwards, there is concern that authoritarian structures could remain in force after the end of COVID-19. The pandemic is therefore expected to further lower democratic standards in the parliamentary or local elections planned for this year in Bosnia and Herzegovina (BiH), Montenegro, Serbia, and North Macedonia.

However, similar to what happened during natural disasters, the WB states have shown during the pandemic that they are fundamentally capable of putting aside nationalistic antagonisms during crises. An encouraging sign in this respect was the cooperation between medical institutions from Serbia and Kosovo during the peak of the Corona crisis. The pandemic should not be used as an excuse to further delay the EU enlargement process. Thus, the EU's "green light," received by Albania and North Macedonia at the end of March, concerning a start to negotiations on membership, and the appointment of a special EU envoy for the WB should be utilized to make the integration process more dynamic and to re-strengthen ties between the WB and the EU.

Otherwise, multi-vectoral influences (Russia, and especially China) on the WB with possible negative influences on regional consolidation could increase still further. Against all empirical facts, the Serbian leadership presented China as the main international supporter during the Corona crisis, despite the EU's 3.3 billion euro support package for the WB. Another factor is the absence of a joint EU-US strategy vis-à-vis important consolidation issues, such as the normalization of relations between Serbia and Kosovo.

\section{Policy Recommendations}

\section{With reference to Albania}

- Albanian gov.: Investments should be made to keep the medical staff in the country. The measures should go beyond simple pay rises.

- Albanian gov.: In the light of a possible new pandemic, the regulations pertaining to the crisis should be made fully coherent and transparent in order to prevent confusion and ensure compliance.

- Donors: As Albania is among the five poorest countries in Europe, it should be assisted with medical and personal protective equipment, training, and all other forms of medical assistance. 
- Albanian gov.: Authoritarian and non-transparent measures should be refrained from, e.g., the illegal demolition of the National Theatre and the disproportionate use of force by parts of the police against protesters.

- Albanian political parties: Ways should be found to generate bipartisan consensus for electoral reform, which is the main condition for the intergovernmental conference with the EU (without which the "green light" for negotiations means nothing).

- Albanian gov. and opposition: The pandemic and the concomitant measures should not be used as an excuse for the continued absence of a Constitutional Court and a working High Court.

\section{With reference to $\mathrm{BiH}$}

- BiH Council of Ministers: A more robust role in determining policies during the pandemic should be assumed; there should be coordinating efforts with lower-level authorities and international institutions. Given a possible second pandemic wave, state-level coordination should be provided to harmonize measures in each state entity and the Brčko District.

- Parliamentary Assembly of BiH: A subordinate role during the pandemic should not be accepted. There should, therefore, be continuous sessions throughout the crisis and meetings on a regular basis.

- BiH institutions: The existing plan on reacting to the pandemic in BiH should be revised and updated, based on the experiences during the current COVID19 crisis. The plan needs to include specific coordination and communication measures in order to avoid confusion and lack of clarity.

- BiH institutions: Mechanisms to fight corruption should be strengthened, especially regarding public procurement. The cases of corruption, which have arisen during the pandemic, should be processed as efficiently and as effectively as possible in order to restore public trust in institutions.

- BiH institutions: Measures designed to minimize any danger to public health should be applied consistently and without exceptions, as was the case with some religious institutions during the pandemic.

- Entity authorities: Recommendations of the Constitutional Court of BiH (Decision AP 1217/20, 22 April 2020) should be taken into account in determining future measures that limit freedom of movement in case a state of emergency needs to be declared again. ${ }^{2}$

- BiH institutions: An environment conducive to free media in line with basic democratic principles should be created. In this respect, the recommenda-

2 The Constitutional Court concluded that there had been a violation of the Freedom of Movement under Article II $(3)(\mathrm{m})$ of the Constitution of Bosnia and Herzegovina and Article 2 of Protocol No. 4 to the European Convention for the Protection of Human Rights and Fundamental Freedoms in relation to the prohibition of movement of persons under 18 years and over 65 of age on the territory of the Federation of $\mathrm{BiH}$. 
tions of the Human Rights Ombudsman of $\mathrm{BiH}$ on protecting the health of journalists should be considered.

- BiH institutions: Clear (written) guidance in cooperation with the Personal Data Protection Agency in $\mathrm{BiH}$ on the use of personal data during crises should be provided.

- BiH institutions: The measures for the organization of local elections in November 2020 should be adapted and the necessary funding provided. Free election campaigns and equal access to the public as defined by the Electoral Law need to be guaranteed.

- Civil Society: Following the pandemic, the economic and financial needs and priorities of the most vulnerable parts of the population should be determined.

- Civil Society: A more dynamic watchdog function during crises should be assumed, especially in regard to cases of corruption and also for the purpose of preventing human rights violations.

\section{With reference to Kosovo}

- EU: Conflicting signals within the Union on the contradictory topic of a territorial exchange between Kosovo and Serbia should be avoided, as these produce political insecurity and increase tensions in the region.

- EU: Visa-free regime should be granted to Kosovo without further delay.

- EU/US: The clear common EU-US line on the Belgrade-Prishtina/Priština dialogue should be restated.

\section{With reference to Montenegro}

- Montenegrin institutions: The role of parliament in scrutinizing government action should be re-strengthened and control re-exerted, in particular concerning human rights issues.

- Montenegrin institutions: A faster response of the Supreme Court is required regarding the contentious issue whether the governmental decisions made during Covid-19 are constitutional. This, in particular, concerns the detention of persons during the limitation of freedom of movement.

- Montenegrin institutions: In accordance with their jurisdiction, the Ombudspersons should use their position more proactively in the pandemic and post-pandemic period for the protection and promotion of human rights and freedoms.

- Montenegrin institutions: The primacy of international law over national laws should be respected, including decisions of the European Court of Human Rights, especially in the field of data protection and privacy.

- Montenegrin institutions: Participatory and transparent disaster response strategies should be developed. This should include close cooperation with Civil Society Organizations and the development of digital platforms to make 
governmental services more accessible. Vulnerable groups, in particular, need proactive information, economic, and social support.

- EU/OSCE: Violations of data protection as well as privacy rights and of democratic principles should be monitored more closely.

- EU: The implementation of recommendations on improving the health care system in Montenegro as provided by the non-profit organization ECRI and the recommendations made by the EU Commission in its Montenegro report should be supported.

\section{With reference to North Macedonia}

- Parliament of North Macedonia: Given the fact that a significant percentage of the governmental decrees were not directly linked with the pandemic and that many of them were judged unconstitutional, the government's decrees should be revised.

- Institutions of North Macedonia: Parliamentary elections should only be conducted when there is a minimal risk to public health. All political actors should refrain from using the Covid-19 pandemic for political purposes and should seek a constructive role in dealing with the crisis.

- Institutions of North Macedonia: An open discussion concerning the limits put on the European Convention on Human Rights during the peak of the Corona crisis in North Macedonia should be conducted.

- Institutions of North Macedonia: The experience with Covid-19 should be used to revise the crisis management system in order to establish an efficient and professional system with clear obligations, responsibilities, and information flow between the institutions involved, as well as protocols and standard operating procedures.

- Institutions of North Macedonia: Investments should be made in medical supplies, equipment, and medical staff, as well as in digital tools for schools.

- EU/Gov. of North Macedonia: The negotiation process with North Macedonia about membership should be started as soon as possible. The government of the candidate country should stay fully committed to European standards, the rule of law and the respect for human rights and freedoms, even in times of crises.

\section{With reference to Serbia}

- Political leadership of Serbia: The political leadership should clearly restate that the main foreign policy goal is EU membership. Signals, such as emphasizing other power centers (e.g., China and Russia) during the Corona crisis should be avoided. Domestic and external policies should be aligned with this clear EU orientation.

- EU Commission: Given that Serbia is defined as an "illiberal democracy" by Freedom House, there should be much greater involvement in questions 
pertaining to democracy. Statements should be made vis-à-vis the Serbian leadership that EU membership is not possible for a semi-authoritarian state.

- $\quad$ EU Commission: The demand should be made that the separation of powers must be reinstated immediately, that the freedom of the media must be respected, and that crime and corruption should be reduced to socially acceptable levels.

- EU/OSCE: Substantial engagement with international observers should be shown during the upcoming parliamentary elections, which, given the Corona crisis and semi-authoritarian conditions, will not be fair.

- Serbian gov./Kosovar gov.: The political dialogue should be continued as soon as possible. Unilateral moves which do not contribute to a sustainable agreement should be avoided. All capacities of both societies should be used in these negotiations in order to avoid an agreement that has to be imposed on citizens on both sides.

- $\quad$ EU/US: A unified trans-Atlantic voice should be found again, which is crucial to achieving a final agreement on the full normalization of relations between Belgrade and Prishtina/Priština. Furthermore, both sides should be offered a clear path leading to full EU membership as well as help to overcome antagonism.

\section{With reference to all WB countries}

- WB gov., EU, and RCC: A regional approach towards addressing the Covid19 pandemics should be adopted, especially in medical cooperation, common rules regarding travel for business, tourism, and other purposes.

\section{Disclaimer}

The views expressed are solely those of the authors and do not represent official views of the PfP Consortium of Defense Academies and Security Studies Institutes, participating organizations, or the Consortium's editors.

\section{Acknowledgment}

Connections: The Quarterly Journal, Vol. 19, 2020 is supported by the United States government. 